\title{
One Year Clinical Outcomes of Renal Artery Stenting: The Results of ODORI Registry
}

\author{
M. Sapoval - I. Tamari $\cdot$ P. Goffette $\cdot$ M. Downes $\cdot$ Q. Senechal $\cdot$ \\ F. Fanelli $\cdot$ P. Reimer $\cdot$ Z. Negaiwi $\cdot$ P. De Cassin $\cdot$ S. Heye $\cdot$ \\ V. Korobov $\cdot$ D. Tsetis $\cdot$ H. Abada
}

Received: 26 April 2009/Accepted: 23 September 2009/Published online: 12 November 2009

(c) The Author(s) 2009. This article is published with open access at Springerlink.com

\begin{abstract}
The safety, efficacy and long term clinical benefits of renal artery revascularization by stenting are still a matter of debate. The aim of our study was to define the safety and efficacy of renal artery stenting with the Tsunami peripheral stent (Terumo Corporation, Tokyo, Japan). The ODORI was a prospective, multicentre registry which enrolled 251 consecutive patients, (276 renal arteries) in 36 centres across Europe. The primary endpoint was acute procedural success defined as $<30 \%$ residual stenosis after stent placement. Secondary endpoints included major adverse events, blood pressure control, serum creatinine level, and target lesion revascularization (TLR) at 6 and 12 months. Patients were $70 \pm 10$ years old, $59 \%$ were
\end{abstract}

\footnotetext{
M. Sapoval ( $\square)$

Hôpital Européen Georges Pompidou,

Cardiovascular Radiology, 20 rue Leblanc,

75015 Paris, France

e-mail: marc.sapoval2@egp.aphp.fr

I. Tamari

Department of Invasive Cardiology,

Wolson Hospital Holon, 62 HaLohamim Street,

P.O. Box 5, Holon 58100, Israel

P. Goffette

Department of Vascular and Interventional Radiology,

Université Catholique de Louvain, Clinique St. Luc,

Avenue Hippocrate 10, 1200 Brussels, Belgium

M. Downes

Vascular and Interventional Radiology, Kent and Canterbury

Hospital, Ethelbert Rd, Canterbury, Kent CT1 3NG, UK

Q. Senechal

Department of Interventional Radiology, Centre Cardiologique du Nord, Saint Denis Boulevard Anatole France,

10, 93200 Saint-Denis, France
}

male, $33 \%$ had diabetes, and $96 \%$ hypertension. The main indications for renal stent implantation were hypertension in $83 \%$ and renal salvage in $39 \%$. Direct stent implantation was performed in $76 \%$ of the cases. Acute success rate was $100 \%$ with residual stenosis of $2.5 \pm 5.4 \%$. Systolic/diastolic blood pressure decreased from a mean of 171/89 at baseline to $142 / 78 \mathrm{mmHg}$ at 6 months $(p<0.0001$ vs. baseline), and 141/80 mmHg at 12 months ( $p<0.0001$ vs. baseline). Mean serum creatinine concentration did not change significantly in the total population. However, there was significant improvement in the highest tercile (from $283 \mu \mathrm{mol} / \mathrm{l}$ at baseline to 205 and $209 \mu \mathrm{mol} / 1$ at 6 and 12 months respectively). At 12-months, rates of restenosis
F. Fanelli

Department of Radiological Sciences, "Sapienza" - University of Rome, 324 Viale Regina Elena, 00161 Rome, Italy

P. Reimer

Central Institute for Imaging Diagnostic, Klinikum Karlsruhe, Moltkestr. 90, Medizinisches Versorgungszentrum,

76133 Karlsruhe, Germany

Z. Negaiwi

Hôpital Cardiologique, Centre Hospitalier Regional

Universitaire de Lille, 2, avenue Oscar Lambret,

59037 Lille Cedex, France

P. De Cassin

Department of Radiology, Centre Médico-chirurgical

et Maternité de Parly 2, 21, Rue Moxouris,

78570 Le Chesnay, France

S. Heye

Department of Radiology, University Hospital

Gasthuizberg, Herestraat 4, 3000 Leuven, Belgium 
and TLR were 6.6 and $0.8 \%$ respectively. The 12 month cumulative rate of all major clinical adverse events was $6.4 \%$ while the rate of device or procedure related events was $2.4 \%$. In hypertensive patients with atherosclerotic renal artery stenosis Tsunami peripheral balloon-expandable stent provides a safe revascularization strategy, with a potential beneficial impact on hypertension control and renal function in the highest risk patients.

Keywords Renal artery - Revascularization - Stent . Registry · Hypertension · Renal function

\section{Introduction}

Atherosclerotic renal artery stenosis (RAS) is a common condition that may lead to hypertension, progressive renal dysfunction and cardiovascular morbidity [1]. It frequently, in up to $40 \%$ of patients, accompanies coronary artery and lower limb atherosclerotic disease [2, 3].

There is still controversy on the clinical efficacy of endovascular therapy of RAS. The randomized trials of balloon angioplasty or stenting for renal artery stenosis compared with medical therapy alone could not show apparent advantage of this type of therapy. Some of those trials were limited by enrollment of small number of patients, frequent crossover from medical to interventional therapy compromising the intention-to-treat results, or selection of patients that are not expected to show clear benefit [4-7]. The preliminary results of ASTRAL [8] trial also showed ambiguous findings related to incremental value of revascularization in addition to medical therapy alone. Publication of this study and anticipated results of CORAL trial are expected to shed more light to this controversial issue.

Concerning revascularization strategy several studies demonstrated equal or better hemodynamic result for stents as compared with balloon angioplasty with higher success rate and long-term patency [9-13]. Currently the use of stents is the preferred treatment option for patients

\footnotetext{
V. Korobov

Republican Clinical Hospital, \#2 (RKB-2)

Chekhov St 1a, 420043 Kazan, Russia

D. Tsetis

Department of Radiology, University Hospital of Heraklion, Medical School of Crete, Stavrakia, 71110 Heraklion, Greece

H. Abada

Division of Vascular and Interventional Radiology,

University of Kentucky Medical Center,

800 Rose street, Lexington, KY 40536, USA
}

requiring revascularization of RAS, mainly for ostial lesions which tend to recoil due to their elastic nature.

The primary aim of this prospective, multicentre, ODORI registry was to assess the immediate technical success, and impact on blood pressure and renal function up to one year, in a large cohort of patients undergoing Tsunami peripheral stent placement.

\section{Methods}

\section{Inclusion/Exclusion Criteria}

Patients, at least 18 years old, with atherosclerotic renal artery stenosis of more than $50 \%$, judged by the clinicians as indicated for renal revascularization, were enrolled in the study.

Excluded were patients with fibromuscular dysplasia, total occlusion, spontaneous dissection or in-stent restenosis of renal artery, stenosis of a transplant or bypass graft anastomosis, aneurysm of abdominal aorta larger than $45 \mathrm{~mm}$ in diameter, current pregnancy, and contraindication to contrast media, aspirin, thienopyridines, heparin or any other therapy as required for elective intervention.

The ODORI registry was conducted in 36 institutions (listed in Appendix 1) from February 2005 to February 2007. The study was carried out according to the Declaration of Helsinki, and respecting all country-specific regulatory requirements. The protocol was reviewed and approved by the ethics committee of participating hospitals and written informed consent was obtained from the patients prior to stent implantation.

\section{Tsunami Peripheral Stent}

Tsunami peripheral stent is a stainless-steel, laser cut, open-cells stent mounted on a rapid exchange delivery balloon catheter compatible with $0.014^{\prime \prime}$ and $0.018^{\prime \prime}$ guidewire. The stent design comprises 12 cells with a triple link in diameters 5 and $6 \mathrm{~mm}$, and 14 cells with quadruple link in $7 \mathrm{~mm}$ diameter, with a strut thickness of $0.0071^{\prime \prime}$ $(0.18 \mathrm{~mm})$. All stents are compatible with $5 \mathrm{Fr}$ long sheath or $6 \mathrm{Fr}$ guiding catheter. Stents were available in diameters of 5,6 and $7 \mathrm{~mm}$ and in lengths of 12 and $18 \mathrm{~mm}$. Fig. 1 .

\section{Procedure}

Stent implantation was performed in a standard fashion via retrograde femoral, brachial or radial approach. Tsunami peripheral stent was implanted at recommended pressure and correct stent size was selected based on visual assessment. 


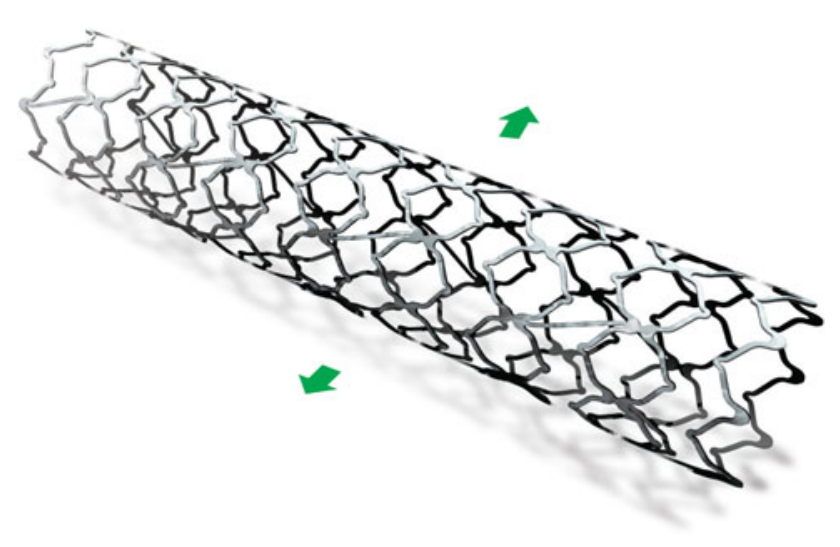

Fig. 1 Expanded Tsunami peripheral stent

Peri-procedural and post-procedure anticoagulant and antiplatelet therapy were according to the routine hospital practice and were left to the discretion of treating physician.

In the initial protocol patient follow-up included visits at 30 days and visit or telephone follow-up at 6 months. The protocol was later amended to include 12 months followup by either hospital visit or telephone follow-up. At that time 12 centres enrolling total of 134 patients agreed to extend patients follow-up. At follow-up special attention was paid to adverse event surveillance along with a detailed questionnaire about concurrent antihypertensive medications and self measured blood pressure. If the patient visited hospital blood samples were drawn for routine laboratory screening, and measurement of resting systolic and diastolic blood pressure were performed. At six and 12 months duplex ultrasonography of the renal artery and stent was conducted to assess patency.

A confirmatory angiogram was recommended if duplex ultrasound suggested restenosis.

\section{Study Definitions and Endpoints}

The definitions in this study are based on Guidelines for the Reporting of Renal Artery Revascularization in Clinical Trials [14].

Primary endpoint of the study was acute technical success defined as angiographic residual diameter stenosis lower than $30 \%$, calculated as the ratio of the residual target lesion lumen diameter to the diameter of the reference segment of the artery using visual estimates.

Secondary endpoints included major complications within $48 \mathrm{~h}$ after stent implantation, improvement in blood pressure, number of medications and serum creatinine level at 6 and 12 months, restenosis defined as more than 50\% diameter stenosis at 6 and 12 months (assessed by ultrasound or angiography) and clinical patency rate at 6 and
12 months defined as absence of clinical need for target lesion revascularization (TLR).

Blood pressure outcomes were defined as follows:

- Cure-diastolic blood pressure $\leq 90 \mathrm{mmHg}$ and systolic blood pressure $\leq 140 \mathrm{mmHg}$, in patients without antihypertensive medications.

- Improvement-diastolic blood pressure $\leq 90 \mathrm{mmHg}$ and/or systolic blood pressure $\leq 140 \mathrm{mmHg}$ on the same or reduced number of medications or a reduction in diastolic blood pressure by at least $15 \mathrm{mmHg}$ with the same or a reduced number of medications.

- Failure-no change or inability to meet these criteria for cure or improvement.

- Benefit-cure or improvement

Renal function outcomes were defined as follows:

- Improvement of renal function, defined as increase of $20 \%$ or more from baseline estimated glomerular filtration rate (e-GFR)

- Worsening of the renal function, defined as decrease of $20 \%$ or more from baseline e-GFR

- Stabilization of the renal function defined as absence of deterioration.

The duplex criteria for restenosis were according to the local preferences and defined as peak systolic velocity (PSV) $>180 \mathrm{~cm} / \mathrm{s}$ and $>3.5: 1$ renal artery to aortic peak systolic velocity ratio. Only successful duplex recordings were considered for restenosis assessment.

\section{Major Clinical Adverse Events}

Major clinical adverse events (MACE) are defined as an event resulting in an additional procedure, unplanned treatment, prolonged hospitalization, transfusion, or death (e.g., arterial thrombosis treated with thrombolytic therapy, renal failure, femoral pseudoaneurysm, or hematoma requiring surgical exploration or other directed therapy, retroperitoneal bleeding). Deaths occurring within 30 days of the renal stent procedure, or during the index hospitalization are considered as a procedure-related mortality.

\section{Study Organization}

All data were entered electronically on predefined case report forms. Data were stored in a central database of KIKA Medical, Paris, France. Queries were continuously generated throughout the study and sent to the investigators for resolution.

All major adverse events were assessed by an independent clinical events monitor. 


\section{Statistical Design and Analysis}

Analytical Plan

This was an observational, non-randomized study. Therefore, the statistical analysis was based on descriptive statistical techniques. Categorical variables are presented as a rate with its $95 \%$ exact confidence interval, whenever appropriate. Continuous variables are presented as means \pm 1 standard deviation with their $95 \%$ confidence interval, whenever appropriate. To assess the risk factors contributing to the endpoints, Student's t-test was used for continuous variables and Fisher exact test for dichotomical variables. The analyses were made on either patient (age, gender, diabetes mellitus, hypertension, renal function) or lesion related (lesion length, reference diameter) parameters and the results are presented separately for entire population and stratified per risk groups according to the baseline values. To more correctly assess changes in some of the most relevant parameters and to avoid bias in followup compliance, the calculations are also performed separately for matched data at baseline and follow-up using paired t-test or McNemar's test. This analysis took into consideration only baseline values of patients which were available for follow-up at corresponding time points ( 6 or 12 months).

All tests were considered statistically significant when $p<0.05$ (alpha was set at 0.05).

\section{Results}

The main baseline characteristics are given in Table 1. Patients were on average 70 years old, 59\% male, with $49 \%$ current or previous smokers, $64 \%$ treated for lipid abnormalities, 96\% treated for hypertension and 33\% diabetic patients. Only $25 \%$ of patients had systolic blood pressure below $150 \mathrm{mmHg}$, while $51 \%$ of patients had serum creatinine level at or above $120 \mu \mathrm{mol} / \mathrm{l}$. The estimated glomerular filtration rate (GFR) lower than $30 \mathrm{ml} / \mathrm{min} / 1.73 \mathrm{~m}^{2}$ was detected in $23 \%$ of the patients.

The main indications for the intervention (categories not mutually exclusive) were hypertension $(83 \%)$, renal salvage (39\%) and cardiac indications (19\%). Hypertension combined with renal insufficiency was present in $25.5 \%$, while simultaneous presence of hypertension, renal insufficiency and cardiac insufficiency was diagnosed in $8.4 \%$ of the treated patients. Most of the patients referred for hypertension were treated for refractory hypertension. Patients indicated for treatment for renal salvage (94 patients) were diagnosed as renal dysfunction not attributable to another cause (57), renal failure after ACE
Table 1 Baseline patient characteristics

\begin{tabular}{ll}
\hline Patient characteristic & \\
\hline Number of patients enrolled & 251 \\
Age (years) & $70.0 \pm 10.4$ \\
Sex $(\mathrm{M})$ & $58.6 \%$ \\
Diabetes & $32.9 \%$ \\
Smoking history & $49.0 \%$ \\
Hypercholesterolemia & $64.2 \%$ \\
Pulmonary edema history & $4.8 \%$ \\
Hypertension & $95.6 \%$ \\
Systolic blood pressure $(\mathrm{mmHg})$ & $171 \pm 26$ \\
Diastolic blood pressure $(\mathrm{mmHg})$ & $89 \pm 14$ \\
Creatinine $(\mu \mathrm{mol} / \mathrm{l})$ & $153 \pm 123$ \\
Baseline estimated GFR $\left(\mathrm{ml} / \mathrm{min} / 1.73 \mathrm{~m}^{2}\right) *$ & $54.3 \pm 33.3$ \\
e-GFR $\geq 60$ & $33.0 \%$ \\
e-GFR $\geq 30<60$ & $44.8 \%$ \\
e-GFR $<30$ & $22.2 \%$ \\
\hline
\end{tabular}

Numbers are means \pm standard deviation, or percentages

* Estimated glomerular filtration rate using Cockcroft-Gault formula [12]

inhibitors (13) and sudden unexplained worsening of renal function (24).

During the procedure $28.7 \%$ of the patients received dual antiplatelet therapy (aspirin and clopidogrel), $43.4 \%$ and $9.6 \%$ respectively, aspirin and clopidogrel alone, while $18.3 \%$ of the patients were treated without antiplatelet therapy.

In total 277 Tsunami peripheral stents were used to treat 276 lesions in 221 patients with single unilateral lesions and in 28 patients with bilateral lesions. Single functioning kidney was present in $30(12 \%)$ patients. The reason for stenting was primary stenting in $87 \%$, recoil after angioplasty in $8.3 \%$, and residual pressure gradient or flow limiting dissection in $2.5 \%$ of the cases. The baseline characteristics of the treated arteries are given in Table 2 . Renal artery stenosis was evenly distributed between right and left renal arteries, being in an ostial position in $81.2 \%$. Mean reference diameter was $5.9 \pm 0.7 \mathrm{~mm}$. The mean percent diameter stenosis of the target vessel (by angiography) was $82.3 \pm 9.8 \%$ before procedure and $2.5 \pm 5.4 \%$ post stent implantation.

The primary endpoint of the study, the acute technical success (residual diameter stenosis $<30 \%$ ) was obtained in $100 \%$ of the lesions. Technical features of the stent were satisfactory with good fluoroscopic visibility, allowing precise positioning particularly in ostial lesions. Direct stenting was performed in $76 \%$ of lesions. Massive calcification was present in $20 \%$ of the lesions, but $76 \%$ of those lesions were also treated by direct stenting. In two patients an additional stent placement was required in the same 
Table 2 Lesion and procedure characteristics

\begin{tabular}{ll}
\hline Lesions characteristic & \\
\hline Number of arteries treated per subject & \\
1 artery & $88.8 \%$ \\
2 arteries & $11.2 \%$ \\
Side artery/ kidney treated & \\
Left & $52.9 \%$ \\
Right & $47.1 \%$ \\
Location artery treated & \\
Ostium & $81.2 \%$ \\
Trunk & $18.8 \%$ \\
Heavily calcified lesions & $20.0 \%$ \\
RVD & $5.9 \pm 0.7$ \\
Diameter artery stenosis (\%) & $82.3 \pm 9.8$ \\
$>50<70 \%$ & $16(5.8 \%)$ \\
$\geq 70<80 \%$ & $63(29 \%)$ \\
$\geq 80-100 \%$ & $195(71 \%)$ \\
Procedure characteristics & \\
Number stents used & 277 \\
Mean stents per patient & $1.1 \pm 0.3$ \\
Mean Stent diameter (mm) & $5.9 \pm 0.65$ \\
Mean Stent length (mm) & $14.9 \pm 3.75$ \\
Direct stenting & $75.8 \%$ \\
Direct stenting in heavily calcified lesions & $75.6 \%$ \\
Mean deployment pressure (atm) & $10.5 \pm 2.6$ \\
Technical success & $100 \%$ \\
\hline & \\
\hline & \\
\hline &
\end{tabular}

Number are percentages (number of total), or means \pm SD

$R V D$ reference vessel diameter

session, one for dissection and one due to distal migration of the first implanted stent in a very obese patient.

One peri-procedural stent thrombosis that was successfully resolved by thrombolysis was the only major clinical adverse event during index hospitalization (Table 3). The patient did not receive clopidogrel during the procedure. There were 6 additional procedural complications: three minor dissections, one partial embolization and two femoral hematomas not requiring transfusion or surgery. All complications were resolved without sequelae and none required prolonged hospital stay.

One patient died in the first month after stent implantation due to pulmonary artery embolism, accounting for a $0.5 \%(1 / 251) 1$-month mortality.

\section{Six and 12-Months Follow-Up}

At six months 164 patients were available for assessment. Four patients died, two from cardiac causes, one from renal failure and one from gastrointestinal causes. One patient underwent percutaneous revascularization of the target
Table 3 In-hospital and long-term major adverse events

\begin{tabular}{lcc}
\hline Event & Number & $\%$ \\
\hline Up to 1 month follow-up & & \\
$\quad$ Death (total) & 1 & 0.4 \\
Cardiovascular death & 1 & 0.4 \\
Stent thrombosis & 2 & 0.4 \\
Total major clinical events & & \\
From 1 month to 1 year follow-up & 11 & 4.4 \\
Death (total) & 4 & 1.6 \\
$\quad$ Cardiovascular death & 3 & 1.2 \\
$\quad$ Death due to renal failure & 1 & 0.4 \\
Pulmonary death & 1 & 0.4 \\
MI & 2 & 0.8 \\
Target lesion revascularization & & \\
Total Events up to 1 year & 16 & 6.4 \\
Total major adverse events up to 1 year follow-up & \\
Total number of patients with major adverse events up & 15 & 6.0 \\
$\quad$ to 1 year follow-up & & \\
Total major adverse events up to 1 year follow-up & 6 & 2.4 \\
related to device or procedure & & \\
\hline
\end{tabular}

lesion due to an in-stent restenosis of more than $70 \%$ assessed by angiography.

No other serious adverse events were reported (Table 3).

At 12 months follow-up 111 out of 134 patients consented for extended follow-up were available for assessment. Seven more patients died, two each from renal failure and pneumonia and one each from pulmonary edema, cardiac failure and unknown causes. One more patient had repeat procedure for in-stent restenosis $(76 \%$ stenosis by angiography).

Table 4 presents the impact of renal artery stenting on systolic and diastolic blood pressure. Systolic/diastolic blood pressure decreased from a mean of $171 / 89 \mathrm{mmHg}$ at baseline to $142 / 78 \mathrm{mmHg}$ at 6 months $(p<0.0001$ vs. baseline), and $141 / 80 \mathrm{mmHg}$ at 12 months ( $p<0.0001$ vs. baseline). Pulse pressure decreased significantly $(p<0.001)$ at both 6 and 12-months follow-up. Mean number of medications per patient at 6 months decreased from $2.63 \pm 0.95$ to $2.23 \pm 1.15(p=0.002)$ and at 12 months from $2.67 \pm 0.95$ to $2.45 \pm 1.23$ ( $\mathrm{p}=\mathrm{NS}$ ) (Fig. 2). The baseline data in this analysis were taken only for corresponding patients for whom 6 and/or 12 months follow-up were available.

In the overall population, the mean serum creatinine did not change significantly $(153 \pm 123 \mu \mathrm{mol} / \mathrm{l}$ at baseline and $163 \pm 127 \mu \mathrm{mol} / \mathrm{l}$ at 12 months) (Table 5). The mean estimated glomerular filtration rate at follow-up was mainly unchanged or slightly worsened in patients with higher baseline values, while it significantly improved in patients with values below $30 \mathrm{ml} / \mathrm{min} / 1.73 \mathrm{~m}^{2}$ before procedure (Table 6). 
Table 4 Changes in mean systolic and diastolic blood pressure over follow-up

\begin{tabular}{|c|c|c|c|c|c|}
\hline Blood pressure & Baseline & 6 months & $p$ & 12 months & $p$ \\
\hline Systolic BP & $171 \pm 26$ & $142 \pm 18$ & $<.0001$ & $141 \pm 17$ & $<.0001$ \\
\hline Diastolic BP & $89 \pm 14$ & $78 \pm 10$ & $<.0001$ & $80 \pm 9$ & $<.0001$ \\
\hline Hypertension cure $(\%)^{\mathrm{a}}$ & & $4.9 \%$ & & $5.7 \%$ & \\
\hline Hypertension improvement $(\%)^{\mathrm{b}}$ & & $77.4 \%$ & & $70.8 \%$ & \\
\hline Pulse pressure (mmHg) & $85.02 \pm 22.08$ & $63.36 \pm 16.15$ & $<0.001^{\mathrm{c}}$ & $61.34 \pm 14.42$ & $<0.001^{\mathrm{c}}$ \\
\hline
\end{tabular}

${ }^{\text {a }}$ Cure $=$ diastolic blood pressure $\leq 90 \mathrm{mmHg}$ and systolic blood pressure $\leq 140 \mathrm{mmHg}$, off antihypertensive medications

b Improvement = diastolic blood pressure $\leq 90 \mathrm{mmHg}$ and/or systolic blood pressure $\leq 140 \mathrm{mmHg}$ on the same or reduced number of medications or a reduction in diastolic blood pressure by at least $15 \mathrm{mmHg}$ with the same or a reduced number of medications

c Paired student's $t$-test

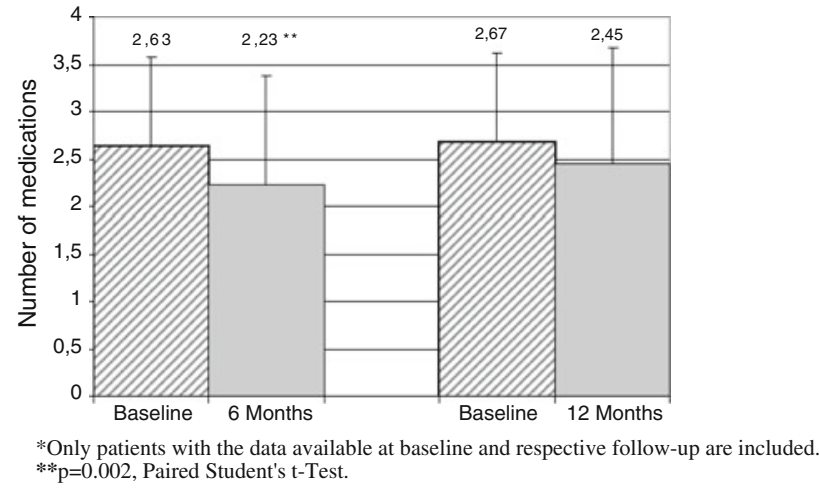

Fig. 2 Mean number of antihypertensive medications at 6 and 12 months for matched patients. Only patients with the data available at baseline and respective follow-up are included. $* * p=0.002$, paired student's $t$-test

\section{Duplex Ultrasound Results}

Successful duplex ultrasonography at six months was performed on 91 arteries and two (2.2\%) arteries showed restenosis of more than $50 \%$. One patient underwent angiography and TLR for symptomatic $76 \%$ restenosis. The other was a patient that had undergone bilateral stenting at baseline with embolic complication to the left kidney. The 6 month duplex control showed a widely patent right and totally occluded left renal artery. Because the patient was asymptomatic no additional treatment was performed.

At 12 months restenosis was detected in 3 out of 69 $(4.3 \%)$ arteries assessed. Two patients were asymptomatic and no angiography was performed, while a third patient had angiographic confirmation of restenosis (76\%) and underwent successful TLR by a cutting balloon.

\section{Discussion}

Our large, multicentre evaluation showed that the use of Tsunami peripheral stent for the treatment of renal artery stenosis is a safe and effective therapy. Significant improvement or stabilization of hypertension at 6 and 12 months after the procedure has been observed. Furthermore, $100 \%$ procedural success with no major periprocedural complications indicates that renal artery stenting with this, newly developed, device is safe.

Catheter-based therapy for symptomatic, hemodynamically significant, atherosclerotic RAS has become the preferred method of revascularization. Balloon angioplasty has been the traditional treatment of choice, but lately, particularly for the treatment of ostial lesions, stents are more frequently used. Despite the increased use of endovascular therapy for renal artery stenosis the controversies about the net benefit of this treatment still exists [7, 8].

In our study stent placement significantly reduced both systolic and diastolic blood pressures at all time points as compared to baseline. Almost three out of four patients showed benefit of treatment by improvement in hypertension control, findings comparable to previously reported results [10-13]. Also the pulse pressure, frequently indicated as an important predictor of mortality, showed significant improvement at 6 and 12 months [15]. However, despite the general positive effect of renal artery revascularization on blood pressure, only a small group of patients (5\%) showed cure of hypertension. This finding confirms that an association between renal artery stenosis and renovascular hypertension is a complex and multifactorial process, and that further studies are needed to identify patients who will benefit from percutaneous treatment, and to define the optimal timing for the indicated intervention.

The improvement in renal function was not as apparent as the improvement in hypertension control, a finding reported in many studies [14-17]. However, considering the population included in our study and common knowledge that renal impairment is a progressive disease which markedly reduces life expectancy and quality of life, particularly in patients who become dependent on dialysis, any stabilization of renal dysfunction and disease progression should be regarded as a beneficial outcome. According to 
Table 5 Estimated glomerular filtration rate at follow-up $(\mathrm{ml} /$ $\min / 1.73 \mathrm{~m}^{2}$ )
Estimated glomerular filtration rate using Cockcroft-Gault formula [14]

${ }^{\text {a }} p<0.001$ (by Mc Nemar test)

Improvement $=$ Increase of $\mathrm{e}$ GFR by $20 \%$ versus baseline Worsening $=$ Decrease of eGFR by $20 \%$ versus baseline Stabilization $=$ No worsening

\begin{tabular}{|c|c|c|c|}
\hline Estimated GFR & $\begin{array}{l}\text { Baseline } \\
N=251\end{array}$ & $\begin{array}{l}6 \text { months } \\
\text { FUP } N=154\end{array}$ & $\begin{array}{l}12 \text { months } \\
\text { FUP } N=97\end{array}$ \\
\hline \multicolumn{4}{|c|}{ Baseline GFR MILD e-GFR $\geq 60$} \\
\hline & $N=82$ & $N=45$ & $N=29$ \\
\hline Mean \pm SD & $90.32 \pm 36.59$ & $85.55 \pm 37.24$ & $62.03 \pm 26.23$ \\
\hline Improvement & & $8.89 \%$ & $3.45 \%$ \\
\hline Stabilization & & $75.56 \%$ & $58.62 \%$ \\
\hline Worsening & & $15.56 \%$ & $37.93 \%$ \\
\hline \multicolumn{4}{|c|}{ Baseline e-GFR MODERATE e-GFR $\geq 30<60$} \\
\hline & $N=111$ & $N=68$ & $N=48$ \\
\hline Mean \pm SD & $45.37 \pm 8.68$ & $49.82 \pm 26.87$ & $47.33 \pm 15.22$ \\
\hline Improvement & & $27.94 \%$ & $22.92 \%$ \\
\hline Stabilization & & $54.41 \%$ & $62.50 \%$ \\
\hline Worsening & & $17.65 \%$ & $14.58 \%$ \\
\hline \multicolumn{4}{|c|}{ Baseline GFR SEVERE e-GFR $<30$} \\
\hline & $N=55$ & $N=41$ & $N=20$ \\
\hline Mean \pm SD & $20.61 \pm 7.31$ & $35.40 \pm 25.46^{\mathrm{a}}$ & $36.32 \pm 22.84 \dagger$ \\
\hline Improvement & & $51.22 \%$ & $50.00 \%$ \\
\hline Stabilization & & $39.02 \%$ & $50.00 \%$ \\
\hline Worsening & & $9.76 \%$ & $0.00 \%$ \\
\hline \multicolumn{4}{|c|}{ Overall population } \\
\hline & $N=248$ & $N=154$ & $N=97$ \\
\hline Mean \pm SD & $54.74 \pm 34.69$ & $56.42 \pm 35.66$ & $49.46 \pm 22.43$ \\
\hline Improvement & & $28.57 \%$ & $22.68 \%$ \\
\hline Stabilization & & $56.49 \%$ & $58.76 \%$ \\
\hline Worsening & & $14.94 \%$ & $18.56 \%$ \\
\hline
\end{tabular}

Table 6 Changes in mean estimated GFR values in subgroup of patients stratified according to baseline values

\begin{tabular}{lllllrrrr}
\hline $\begin{array}{l}\text { Baseline value } \\
\left(\mathrm{ml} / \mathrm{min} / 1.73 \mathrm{~m}^{2}\right)\end{array}$ & $\begin{array}{l}\text { Post } \\
\text { procedure }\end{array}$ & $p$ Value* & 30 Days & $p$ Value* & 6 months & $p$ Value* & 12 months & $p$ Value* \\
\hline$\geq 60$ & -7.6 & 0.02 & -8.2 & 0.12 & -10.2 & 0.13 & -24.9 & 0.02 \\
$\geq 30<60$ & +3.4 & 0.01 & +14.1 & 0.01 & +3.9 & 0.21 & +1.1 \\
$\geq 15<30$ & +8.4 & 0.06 & +5.3 & 0.02 & +9.7 & $<0.001$ & +12.9 & 0.54 \\
$<15$ & +7.6 & 0.26 & +33.7 & 0.04 & +32.8 & 0.18 & +23.9 \\
\hline
\end{tabular}

"+" indicates improved creatinine clearance, while "_" indicates worsening. * Paired

Student's t-test. Only patients with the data available at baseline and respective follow-up are included

the American Heart Association guidelines, a slowed decline in renal function is sufficient to support the claim that renal artery angioplasty is beneficial [14]. In our study the best results were observed in patients with the lowest baseline e-GFR. Unfortunately the number of patients in this subgroup with long-term follow-up was relatively small, therefore, drawing any conclusion from this finding would be inappropriate. Our results are similar to some of previous reports [16-18], however, Blum et al. [12] and White et al. [9] found no significant change in creatinine, independent of baseline renal function. Those discrepant findings may be a result of small sample size or the inclusion of stenoses from $50 \%$ to $70 \%$ which are not hemodynamically relevant and can therefore not cause ischemic nephropathy [19]. In our series of patients, however, only 16 patients $(5.8 \%)$ had stenosis between $50 \%$ and $70 \%$, bringing further controversies to this subject. Moreover, slight deterioration in renal function observed in patients with highest e-GFR at baseline is difficult to explain. It could be related to the natural progression of the disease or to a certain degree of cholesterol embolism that may put patients at risk of renal function deterioration.

The assessment of renal function and significance of RAS are also not well defined. As recently indicated by Drieghe et al. using the current criteria for RAS, a diameter 
stenosis $>50 \%$ by angiography falsely identifies a renal stenosis as significant in approximately $38 \%$ of cases and ultrasound does so in approximately $55 \%$ of cases [20]. This indicates that the commonly accepted criteria of significant RAS overestimate the actual severity of the lesion. It is likely, therefore, that in our study as well as in the other studies that have investigated the usefulness of renal revascularization for the treatment of renovascular hypertension and renal disease progression, a sizable proportion of patients with hemodynamically non-significant stenosis might have been included. Since, in these patients, no benefit of renal artery stenting can be expected (as they had arterial hypertension or renal function impairment of other etiologies), their inclusion in these trials has most probably hazed the benefits of renal angioplasty over medical treatment.

\section{Technical Characteristics}

The procedural performance of Tsunami stent in our study was good without occurrence of in-hospital deaths, artery perforation or rupture, or other major complications. As expected, a low crossing profile allowed direct stenting in more than $75 \%$ of lesions, including severely calcified lesions, reducing contrast dose, and radiation load and also procedure time. This finding compares favorably with other low profile platforms [21].

Although large number of patients in our study did not undergo ultrasound evaluation, the $6.6 \%$ cumulative incidence of restenosis (2/91 at 6 months and 3/64 at 12 months) is comparable with findings in other contemporary trials or meta-analyses [10, 21-23]

High procedural success and relatively low frequency of adverse events in our study may indicate that refinement of the devices and techniques for renal artery revascularization, along with careful patient selection could possible improve the clinical outcome after endovascular revascularization of RAS. Our aims must therefore be to improve primary and secondary prevention, achieve an earlier diagnosis, and, when indicated, appropriately treat occlusive renal disease.

\section{Study Limitations}

Our study has several limitations, the major being lack of control group which would allow the assessment of the value of the renal artery revascularization. A relatively low follow-up rate reduced the possibility of identifying patients at risk and patients expected to show benefit. This registry did not mandate follow-up by hospital visit and hence the number of ultrasound assessments is small which along with absence of an independent core-lab prevents a clear conclusion related to restenosis.

\section{Conclusion}

The findings of our study indicate that primary stent placement in atherosclerotic RAS is safe procedure which might be beneficial for improved control of hypertension and stabilization of renal function in patients on highest risk. Good technical success, low complication rate, low restenosis and TLR rate indicate that this stent platform could be a useful tool for further randomized controlled trials.

\section{Appendix 1}

Principal Investigator

Marc Sapoval MD, PhD, Hôpital Européen Georges Pompidou, Paris, France

\section{Clinical Events Monitoring}

Hicham Abada, MD, University of Iowa, Iowa, USA

List of Investigators Participating in ODORI Study

Belgium: D. Henroteaux, MD, Liège; P. Goffette, MD, Brussels; S. Heye, MD, Leuven; France: Q. Senechal, MD, Saint-Denis; H. Kobeiter, MD, Créteil; Z. Negaiwi, MD, Lille; P. De Cassin, MD, Le Chesnay; V. Perot, MD, Bordeaux; M. Sapoval, MD PhD, Paris; JM. Pernes, MD, Antony, O. Monnet, MD, and P. Bergeron, MD, Marseille; M. Auguste, MD, Salpetriere, M. Amor, MD, Essey les Nancy; Germany: J. Ruef, MD, Frankfurt; W. Kersjes, MD, Ludwigsburg, P. Reimer, MD, Karlsruhe, D. Haertel, MD, Detmold, G. Oehlert, MD, Hannover, C. PocklerSchoniger, MD, Karlsbad, S. Müller-Hülsbeck, MD, Kiel; Greece: D. Tsetis, MD, Heraklion; Israel: A. Belenky, MD, Rabin, I. Tamari, MD, Holon; Italy: P. Curone, MD, Genoa, A. Iadanza, MD, Siena, A. Rampoldi, MD, Milano, V. Molfese, MD, Potenza, F. Fanelli, MD, Rome; The Netherlands: J. Reekers, MD, Amsterdam; Russian Federation: V. Korobov, MD, Kazan; Slovakia: P. Lesny, MD, Bratislava; Spain: M. Maynar Moliner, MD, Tenerife, J. Falco, MD, Barcelona; Turkey: C. Barbaros, MD, Ankara, K. Guven, MD, Istanbul; United Kingdom: M. Downes, $\mathrm{MD}$, Kent.

Acknowledgment $M$. Sapoval received research grant from Terumo, other authors reported no conflict of interest related to this manuscript.

Open Access This article is distributed under the terms of the Creative Commons Attribution Noncommercial License which permits any noncommercial use, distribution, and reproduction in any medium, provided the original author(s) and source are credited. 


\section{References}

1. Safian RD, Textor SC (2001) Renal-artery stenosis. N Engl J Med 344:431-442

2. Gross CM, Krämer J, Waigand J, Luft CF, Dietz R (1997) Relation between arteriosclerosis in the coronary and renal arteries. Am J Cardiol 80:1478-1481

3. Miralles M, Corominas A, Cotillas J, Castro F, Clara A, VidalBarraquer F (1998) Screening for carotid and renal artery stenoses in patients with aortoiliac disease. Ann Vasc Surg 12:17-22

4. van Jaarsveld BC, Krijnen P, Pieterman H, Derkx FHM, Deinum J, Postma CT et al (2000) The effect of balloon angioplasty on hypertension in atherosclerotic renal-artery stenosis. N Engl $\mathrm{J}$ Med 342:1007-1014

5. Webster J, Marshall F, Abdalla M, Dominiczak A, Edwards R, Isles CG et al (1998) Randomised comparison of percutaneous angioplasty vs continued medical therapy for hypertensive patients with atheromatous renal artery stenosis. J Hum Hypertens 12:329-335

6. Plouin PF, Chatellier G, Darné D (1998) Raynaud a for the essai multicentrique medicaments vs angioplastie (emma) study group. blood pressure outcome of angioplasty in atherosclerotic renal artery stenosis: a randomized trial. Hypertension 31:823-829

7. Bax L, Woittiez JAJ, Kouwenberg JH, Mali PTMW, Buskens E, Beek F, Braam B et al (2009) Stent placement in patients with atherosclerotic renal artery stenosis and impaired renal function. a randomized trial. Ann Intern Med 150:840-848

8. Wheatley K, Kalra PA, Moss J, Ives N, Fitzpatrick-Ellis K, Gray $\mathrm{R}$ (2008) Lack of benefit of renal artery revascularization in atheroslerotic renovascular disease (ARVD) results of the ASTRAL trial (abstr). J Am Soc Nephrol 19:47A

9. White CJ, Ramee SR, Collins TJ, Jenkins JS, Escobar A, Shaw D (1997) Renal artery stent placement:utility in lesions difficult to treat with balloon angioplasty. J Am Coll Cardiol 30:1445-1450

10. Rocha-Singh K, Jaff MR, Rosenfeld K (2005) ASPIRE-2 trial investigators evaluation of the safety and effectiveness of renal artery stenting after unsuccessful balloon angioplasty: the ASPIRE-2 study. J Am Coll Cardiol 46:776-783

11. Dorros G, Prince C, Mathiak L (1993) Stenting of a renal artery stenosis achieves better relief of the obstructive lesion than balloon angioplasty. Cathet Cardiovasc Diagn 29:191-198

12. Blum U, Krumme B, Flugel $P$ et al (1997) Treatment of ostial renal-artery stenoses with vascular endoprostheses after unsuccessful balloon angioplasty. N Engl J Med 336:459-465
13. van de Ven PJG, Kaatee R, Beutler JJ, Gabelmann A, Lehnert T, Buitrago-Tellez C et al (1999) Arterial stenting and balloon angioplasty in ostial atherosclerotic renovascular disease: a randomized trial. Lancet 353(9149):282-286

14. Rundback JH, Sacks D, Kent KC, Cooper C, Jones D, Murphy T et al (2003) Guidelines for the reporting of renal artery revascularization in clinical trials. JVIR 14:477-492

15. Preston SKlassen, Edmund GLowrie, Donal NReddan et al (2002) Association between pulse pressure and mortality in patients undergoing maintenance hemodialysis. JAMA 287(12): 1548-1555

16. Taylor A, Sheppard D, MacLeod MJ, Harden P, Baxter GM, Edwards RD et al (1997) Renal artery stent placement in renal artery stenosis: technical and early clinical results. Clin Radiol 52:451-457

17. Harden PN, MacLeod MJ, Rodger RSC, Baxter GM, Connell JMC, Dominiczak AF et al (1997) Effect of renal-artery stenting on progression of renovascular renal failure. Lancet 349:11331136

18. Baumgartner I, von Aesch K, Do DD, Triller J, Birrer M, Mahler F (2000) Stent placement in ostial and nonostial atherosclerotic renal arterial stenoses: a prospective follow-up study. Radiology. 216:498-505

19. Mustert BR, Williams DM, Prince MR (1998) In vitro model of arterial stenosis: correlation of MR signal dephasing and transstenotic pressure gradients. Magn Reson Imaging 16:301-310

20. Drieghe B, Madaric J, Sarno G, Manoharan G, Bartunek J, Heyndrickx GR, Pijls NH, De Bruyne B (2008) Assessment of renal artery stenosis: side-by-side comparison of angiography and duplex ultrasound with pressure gradient measurements. Eur Heart J 29:517-524

21. Sapoval M, Zähringer M, Pattynama P, Rabbia C, Vignali C, Maleux G et al (2005) Low-profile stent system for treatment of atherosclerotic renal artery stenosis: the GREAT trial. JVIR 16:1195-1202

22. Isles CG, Robertson S, Hill D (1999) Management of renovascular disease: a review of renal artery stenting in ten studies. Q J Med. 92:159-167

23. Leertouwer TC, Gussenhoven EJ, Bosch JL, van Jaarsveld BC, van Dijk LC, Deinum J, Man In 't Veld AJ (2000) Stent placement for renal arterial stenosis: where do we stand? A metaanalysis. Radiology 216:78-85 